\title{
The use (and misuse) of sediment traps in coral reef environments: theory, observations, and suggested protocols
}

\author{
C. D. Storlazzi · M. E. Field • M. H. Bothner
}

Received: 29 June 2010/ Accepted: 1 December 2010/Published online: 17 December 2010

(C) The Author(s) 2010. This article is published with open access at Springerlink.com

\begin{abstract}
Sediment traps are commonly used as standard tools for monitoring "sedimentation" in coral reef environments. In much of the literature where sediment traps were used to measure the effects of "sedimentation" on corals, it is clear from deployment descriptions and interpretations of the resulting data that information derived from sediment traps has frequently been misinterpreted or misapplied. Despite their widespread use in this setting, sediment traps do not provide quantitative information about "sedimentation" on coral surfaces. Traps can provide useful information about the relative magnitude of sediment dynamics if trap deployment standards are used. This conclusion is based first on a brief review of the state of knowledge of sediment trap dynamics, which has primarily focused on traps deployed high above the seabed in relatively deep water, followed by our understanding of near-bed sediment dynamics in shallow-water environments that characterize coral reefs. This overview is followed by the first synthesis of near-bed sediment trap data collected with concurrent hydrodynamic information in coral reef environments. This collective information is utilized to develop nine protocols for using sediment traps in coral reef environments, which focus on trap parameters
\end{abstract}

Communicated by Environment Editor Prof. Rob van Woesik

C. D. Storlazzi $(\varangle) \cdot$ M. E. Field

US Geological Survey, Pacific Coastal and Marine Science Center, 400 Natural Bridges Drive, Santa Cruz, CA 95060, USA

e-mail: cstorlazzi@usgs.gov

M. H. Bothner

US Geological Survey, Woods Hole Science Center, 384 Woods

Hole Road, Woods Hole, MA 02543, USA that researchers can control such as trap height $(H)$, trap mouth diameter $(D)$, the height of the trap mouth above the substrate $\left(z_{o}\right)$, and the spacing between traps. The hydrodynamic behavior of sediment traps and the limitations of data derived from these traps should be forefront when interpreting sediment trap data to infer sediment transport processes in coral reef environments.

Keywords Sediment trap - Coral reefs - Sedimentation · Waves $\cdot$ Currents $\cdot$ Shear stress

\section{Introduction}

Coral reefs typically grow in relatively clear, oligotrophic waters. Land-use practices such as overgrazing and coastal development can increase the supply of terrestrial sediment to the nearshore zone. This fine-grained terrestrial sediment can smother corals and increase turbidity, which in turn will decrease the light available for photosynthesis and can modify coral growth rates and forms, create physiological stress, and even cause coral mortality (Dodge et al. 1974; Acevedo et al. 1989; Fortes 2000; Nugues and Roberts 2003; Crabbe and Smith 2005; Mallela and Perry 2007). Dissolved heavy metals and other toxic substances often adhere to fine-grained sediment, with which they are then transported within the nearshore reef ecosystem (Dickson et al. 1987; Saouter et al. 1993; Bastidas et al. 1999). The potential impacts of sediment accumulation on coral reef health include the expenditure of energy by the coral to remove sediment particles, the loss of hard substrate for new coral recruitment, and the death of coral colonies that become buried (e.g., Rogers 1990; Fabricius 2005). For these reasons, measurements of sedimentation and turbidity have become important components of coral reef studies, 
and sediment traps have become a standard measurement tool.

Sediment traps are containers deployed in the water column for the purpose of (a) acquiring a representative sample of the material settling vertically through the water column and (b) providing an integrated particle collection rate and particle properties over the time of deployment. The first use of containers to collect settling particulate matter in lacustrine and marine environments occurred in the first half of the 20th century (see reviews in Bloesch and Burns 1980; Reynolds et al. 1980; Butman et al. 1986). Starting in the 1970s, sediment traps were increasingly used in relatively shallow $(<40 \mathrm{~m})$ hermatypic coral reef environments to measure the effects of "sedimentation" on corals (e.g., Maragos 1972; Aller and Dodge 1974; Randall and Birkeland 1978). Owing to their simple construction and relatively broad use, sediment traps are now used as a standard method for monitoring "sedimentation" in coral reef environments. Traps are also suggested as an environmental monitoring tool to determine the impact or effectiveness of land-use practices (Pernetta 1993; Rogers et al. 1994; Almada-Villela et al. 2003; Wilkinson et al. 2003; Hill and Wilkinson 2004; Jordan et al. 2010).

In much of the literature in which sediment traps were used to measure the effects of "sedimentation" on corals, it is clear from descriptions of deployments and interpretations of the resulting data that information derived from sediment traps has very frequently been misinterpreted or misapplied. These errors appear to result from (1) a lack of understanding of the history of sediment trap design and implementation and (2) a lack of published data and understanding of sediment and sediment trap dynamics in environments under the hydrodynamic conditions characteristic of coral reefs. Therefore, despite their widespread use, sediment traps have the potential for providing misleading and inaccurate information about particle behavior on shallow coral reef substrates. In this paper, we will briefly review the state of knowledge of sediment trap dynamics and their trapping efficiency, which have been primarily focused on small traps deployed high above the seabed in relatively deep water. This information will then be put into the context of our state of understanding of near-bed sediment dynamics in shallow-water environments that characterize coral reefs. This overview will be followed by the first synthesis of near-bed sediment trap data collected with concurrent hydrodynamic information in coral reef environments. Finally, we will discuss the implications of the older deep-water studies and the new measurements in coral reef environments presented here to potential protocols for the deployment of sediment traps in shallow $(<40 \mathrm{~m})$ coral reef environments and the interpretation of the resulting data.

\section{Background}

A sediment trap is used to capture a representative sample of the net vertical flux of sediment particles in the water column. Importantly, most of the literature published on sediment traps over the latter half of the 20th century addressed small traps relative to the height of the water column in deep water relatively high above the sea or lake floor. Gardner (1980a, b) and Butman (1986) concluded that particle-trapping rate $(P)$ of a trap is a function of residence time and circulation pattern within the trap. These are controlled by a number of independent variables describing trap geometry and additional parameters describing both the fluid and the particles entrained in the fluid (Fig. 1):

Basic dimensions of each variable:

mass $(M$, e.g. $-\mathrm{kg}, \mathrm{lbs})$, time $(T$, e.g. $-\mathrm{s}, \mathrm{h})$, and length $(L$, e.g. $-\mathrm{cm}, \mathrm{ft})$

Particle-trapping rate:

$P=$ mass of particles trapped per unit area per unit time $\left(M L^{-2} T^{-1}\right)$

Trap geometry:

$H=$ trap height $(L)$

$D=$ trap mouth diameter $(L)$

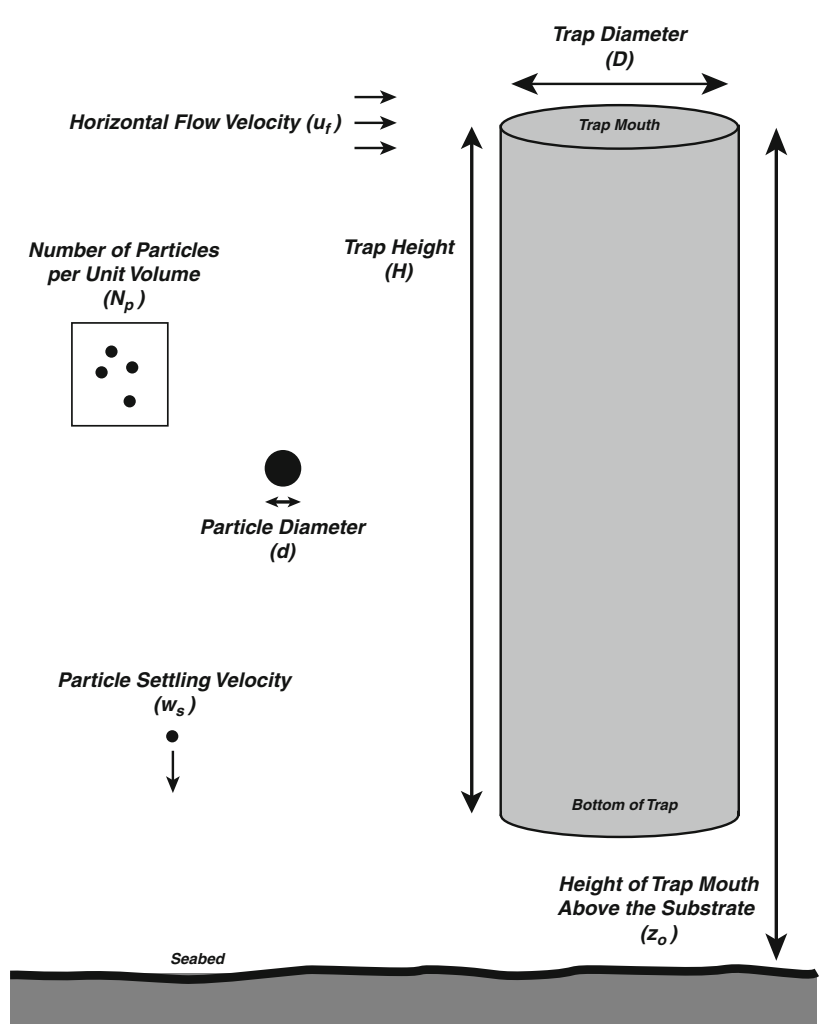

Fig. 1 Schematic diagram of a sediment trap detailing a number of the parameters addressed in this study 
Fluid:

$\rho_{f}=$ fluid density $\left(M L^{-3}\right)$

$\mu_{f}=$ fluid viscosity $\left(M L^{-1} T^{-1}\right)$

$u_{f}=$ horizontal flow velocity at the height of the top of the trap $\left(L T^{-1}\right)$

Particle:

$d=$ particle diameter $(L)$

$\rho_{p}=$ particle density $\left(M L^{-3}\right)$

$N_{p}=$ number of particles in the fluid per unit volume

$\left(L^{-3}\right)$

$g=$ acceleration due to gravity $\left(L T^{-2}\right)$

In the most simple case where there is no flow $\left(u_{f}=0\right)$, particles settle vertically through the water column, and the number of particles trapped per unit area per unit time $(P)$ is a function of the number of particles in the fluid per unit volume $\left(N_{p}\right)$, the cross-sectional area of the trap mouth $(A)$, and particle settling velocity $\left(w_{s}\right.$, from Stokes Law, e.g., Shepard 1963), with $A$ and $w_{s}$ defined as:

$A=\pi\left(\frac{D}{2}\right)^{2}$

$w_{s}=\frac{\left(\rho_{p}-\rho_{f}\right) g d^{2}}{18 \mu_{f}}$

For reference, example values of $w_{s}$ for various sediment compositions and sizes are shown in Table 1. While carbonate sediment in coral reef environments is not always round nor of uniform density, which affect $w_{s}$ (e.g., Kench 1997), these values are presented to provide an order-ofmagnitude example of the variations in $w_{s}$ as a function of $d$. It is extremely rare, however, that a lake or the ocean is completely quiescent (low $u_{f}$ ), and usually there is some velocity associated with the water mass due to waves or currents. For large, dense particles in an extremely slowmoving fluid where $w_{s}$ is greater than horizontal flow velocity at the height of the top of the trap $\left(u_{f}\right)$, the angle of particle approach to the trap is nearly vertical, the effective area for the particles $\left(A_{e}\right)$ is only slightly smaller than the true value $A$, and the trap almost approximates the net vertical flux of sediment particles in the water column (Fig. 2).
The hydrodynamic environments over most coral fore reefs, however, are rarely quiescent, suggesting that $u_{f}$ is at least equivalent to $w_{s}$, if not significantly greater, which affects $A_{e}$ (Fig. 2). Most reefs are located within the tropical trade-wind belt or undergo diurnal insolation cycles ("sea breezes") and thus are subjected to daily wind-driven currents and are exposed to ocean surface waves due to both local and/or far-field storm forcing. This results in most coral reefs being subjected to both instantaneous horizontal wave-orbital velocities on the order of $10-100 \mathrm{~cm} \mathrm{~s}^{-1}$ and tidally-driven and wind-driven currents on the order of 5-20 $\mathrm{cm} \mathrm{s}^{-1}$ (e.g., Wolanski 1994; Lugo-Fernandez et al. 1998; Storlazzi et al. 2004), producing values of $u_{f}$ orders of magnitude greater than $w_{s}$, even accounting for relatively minor differences in $w_{s}$ due to variations in grain shape and density (Kench 1997). A comparison of the representative values of $w_{s}$ and $u_{f}$ (Tables 1 and 2, respectively) suggests that $w_{s}$ can be several orders of magnitude smaller than $u_{f}$ for most coral reefs, which implies that sediment traps in these environments generally do not approximate the net downward flux of particles.

In the 1970s and 1980s, the first comprehensive efforts to investigate the accuracy, precision, and efficiency of traps in conditions where $w_{s}<<<u_{f}$ were made. Tooby et al. (1977), Hargrave and Burns (1979), Gardner (1980a, b), Butman (1986), and Butman et al. (1986) performed important research on sediment trap dynamics using theoretical calculations, laboratory tests, and field experiments. Tooby et al. (1977), Gardner (1980a, b), Butman's (1986), and more recently Gust et al. (1996) flume experiments suggested that particles in these scenarios are collected by a process of fluid exchange, rather than falling freely into a trap (Fig. 3).

Because of the turbulent nature of flow over the trap mouth, eddies are shed from the top of the trap and new ones can form. The intensity of eddies and their frequency of shedding increases with increases in flow velocity toward and over the trap (Butman et al. 1986). The research by Gardner (1980a), Butman (1986), and Bale (1998) suggested that symmetric traps are the most efficient, since in multidirectional currents they have the same geometric
Table 1 Settling velocities of sediment that characterize coral reef environments

a Carbonate assumes a bulk density of $1,850 \mathrm{~kg} \mathrm{~m}^{-3}$ in $25^{\circ} \mathrm{C}$ water

b Volcanic assumes a bulk density of $2,700 \mathrm{~kg} \mathrm{~m}^{-3}$ in $25^{\circ} \mathrm{C}$ water

\begin{tabular}{lllr}
\hline Grain class & $\begin{array}{l}\text { Grain } \\
\text { diameter } \\
(\mathrm{mm})\end{array}$ & $\begin{array}{l}\text { Carbonate } \\
\left(\mathrm{cm} \mathrm{s}^{-1}\right)\end{array}$ & $\begin{array}{l}\text { Volcanic }^{\mathrm{b}} \\
\left(\mathrm{cm} \mathrm{s}^{-1}\right)\end{array}$ \\
\hline Coarse sand & 1.000 & 8.064 & 12.067 \\
Fine sand & 0.200 & 1.239 & 2.222 \\
Coarse silt & 0.040 & 0.136 & 0.689 \\
Fine silt & 0.010 & 0.044 & 0.089 \\
Clay & 0.003 & 0.004 & 0.008 \\
\hline
\end{tabular}


Fig. 2 Schematic views displaying the influence of horizontal flow velocity $\left(u_{f}\right)$ relative to particle settling velocity $\left(w_{s}\right)$ on effective trap area $\left(A_{e}\right)$. At low $u_{f}$ relative to $w_{s}, A_{e} \sim A$ and sediment traps almost approximate the net vertical flux of sediment particles in the water column as the particle trajectory (thick black arrow in the side view) is nearly vertical. As $u_{f}$ increases relative to $w_{s}$, the particle trajectory becomes increasingly more horizontal, $A_{e}$ decreases, and sediment traps no longer approximate the net vertical flux of sediment particles in the water column

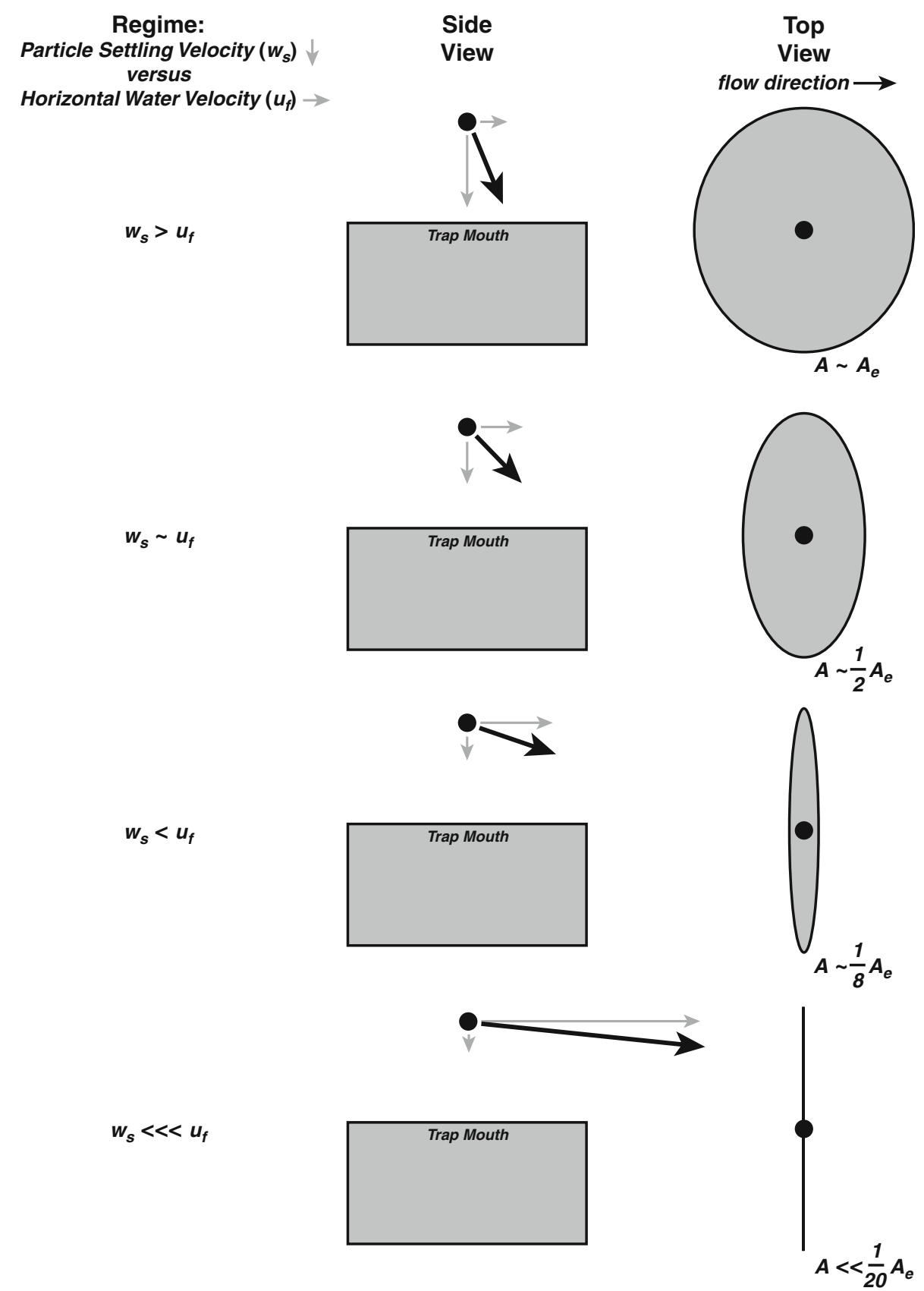

properties relative the flow in all directions. Not only is the shape of the trap important, but also, as Gardner (1980a) and Nodder and Alexander (1999) show, individual traps deployed on the same array can affect the relative trapping efficiency of the adjacent traps by disturbing the mean flow field around them. They proposed a minimum of $3 \mathrm{D}$ separating traps in the cross-stream direction (assuming $u_{f}$ direction is known and unidirectional) and $10 \mathrm{D}$ separating traps in the downstream direction to eliminate flow disruption by the adjacent traps.
Using the above 9 basic independent parameters describing trap geometry, the fluid, and the particles entrained in the fluid, Gardner (1980a, b), Butman (1986), and Butman et al. (1986) defined trapping efficiency $(E)$ as the ratio of actual trapping to the trapping rate when $u_{f}=0$. They also suggest that $E$ should be a function of six dimensionless parameters: $S, F_{r}, R_{t}, T_{r}, R_{p}$, and $P_{r}$. Those authors also provide comprehensive reviews of published and laboratory data addressing a number of these dimensionless parameters. These parameters are as follows: 
Table 2 Influence of parameters that control wave-orbital velocities in coral reef environments

\begin{tabular}{llllll}
\hline $\begin{array}{l}\text { Parameter } \\
\text { to vary }\end{array}$ & $\begin{array}{l}\text { Wave } \\
\text { height }(\mathrm{m})\end{array}$ & $\begin{array}{l}\text { Wave } \\
\text { period }(\mathrm{s})\end{array}$ & $\begin{array}{l}\text { Water } \\
\text { depth }(\mathrm{m})\end{array}$ & $\begin{array}{l}\text { Elevation } \\
\text { above bottom }(\mathrm{m})\end{array}$ & $\begin{array}{l}\text { Wave-orbital } \\
\text { velocity }\left(\mathrm{cm} \mathrm{s}^{-1}\right)\end{array}$ \\
\hline Wave height & 0.5 & 10 & 10 & 0.5 & 23.7 \\
& 1 & 10 & 10 & 0.5 & 47.3 \\
Wave period & 2 & 10 & 10 & 0.5 & 94.6 \\
& 1 & 5 & 10 & 0.5 & 33.8 \\
\multirow{3}{*}{ Depth } & 1 & 10 & 10 & 0.5 & 47.3 \\
& 1 & 15 & 10 & 0.5 & 49.2 \\
& 1 & 10 & 5 & 0.5 & 65.4 \\
Elevation & 1 & 10 & 10 & 0.5 & 47.3 \\
& 1 & 10 & 20 & 0.5 & 46.5 \\
& 1 & 10 & 10 & 0.1 & 47.3 \\
& 1 & 10 & 10 & 0.5 & 48.2 \\
\hline
\end{tabular}

Trapping efficiency:

$E=P w_{s}^{-1} N_{p}^{-1}$

$S=$ specific gravity of the particle $=\rho_{p} \rho_{f}^{-1}$

$F_{r}=$ ratio of horizontal fluid velocity to nominal

vertical particle fall velocity $=u_{f} w_{s}^{-1}$

$R_{t}=$ trap Reynolds number $=u_{f} D v_{f}^{-1}$

$T_{r}=$ trap aspect ratio $=H D^{-1}$

$R_{p}=$ particle Reynolds number $=w_{s} d v_{f}^{-1}$

$P_{r}=$ ratio of particle concentration to particle size $=N_{p} d^{3}$

With

$v_{f}=$ kinematic viscosity of the fluid $=\mu_{f} \rho_{f}^{-1}$

There is some debate on the relative importance of these parameters, with much of the effort focused on the trap Reynolds number $\left(R_{t}\right)$, which is a function of $u_{f}$ relative to the trap diameter $(D)$. Gardner (1980a, b), Butman (1986), Butman et al. (1986), Baker et al. (1988), White (1990), Gust et al. (1996), and Jurg (1996) did not come to a firm conclusion regarding the influence of $R_{t}$ on $E$, but most suggest that $E$ decreases at high values of $u_{f}$, which in most of their experiments was defined as somewhere on the order of $20 \mathrm{~cm} \mathrm{~s}^{-1}$. Because many coral reefs are subjected to not only current speeds $\left(u_{\text {current }}\right)$ on the order of $5-20 \mathrm{~cm} \mathrm{~s}^{-1}$, but also horizontal wave-orbital velocities $\left(u_{\text {wave }}\right)$ on the order of 10-100 $\mathrm{cm} \mathrm{s}^{-1}$ (Table 2), the combined wave and current horizontal flow velocity $u_{f}$, which is defined as:

$u_{f}=\sqrt{\left(u_{\text {current }}\right)^{2}+\left(u_{\text {wave }}\right)^{2}}$

is often much greater than $20 \mathrm{~cm} \mathrm{~s}^{-1}$. Thus, while quite a bit of effort has gone into understanding the influence of $R_{t}$ on $E$, it is clear that current speeds and oscillatory horizontal wave-orbital velocities in many coral reef settings exceed the known envelops of performance of $E$ under varying $R_{t}$.

Four of the six parameters that govern $E$ are functions of the environment where the trap is deployed. However, there are two parameters that researchers can control: $D$ and $T_{r}$ (Eq. 7). Based on previous research addressing flow over traps (e.g., Gardner 1980a; Butman 1986; Baker et al. 1988; Gust et al. 1996), Jurg (1996) suggested a minimum $D$ on the order of $5 \mathrm{~cm}$. Gardner (1980a, b) considered $T_{r}$ as the controlling factor in $P$, with the most efficient trap having a $T_{r}$ of $3: 1$; White (1990) suggested the use of $T_{r}$ of at least $3: 1$, and preferably $5: 1$ in energetic environments. Gust et al. (1996), investigating $E$ in turbulent flows that more closely approximate the conditions observed over coral reefs, suggested that the unsteady turbulent eddies that form in the flow boundary layer that develops over the mouth of the trap can propagate down to more than $7 D$ into the trap (Fig. 3) and thus suggested a $T_{r}>7: 1$. In contrast to earlier studies, Gardner et al. (1983) and Baker et al. (1988) worked in more energetic environments and suggested that traps were likely to preferentially collect sediment with coarser $d$. This is because sediment with larger $d$ has higher $w_{s}$ than finer particles for a given grain shape and density; particles with slow $w_{s}$ relative to the circulation within the trap have a greater chance to escape with the exiting turbulent flow. This results in an underrepresentation of finer particles (silts and clays, $d<0.063 \mathrm{~mm}$ ) in the trapped sample.

The height of the trap mouth above the substrate $\left(z_{o}\right)$ has also been reported to influence $P$ even in deep ocean environments (Gardner et al. 1983, 1985). Hakanson et al. (1989) demonstrated $z_{o}$ to be inversely related to $P$ in shallow-water environments where the resuspension of sediment from the seabed is likely a major component of $P$ and high values of $P$ logarithmically decrease with $z_{o}$. 


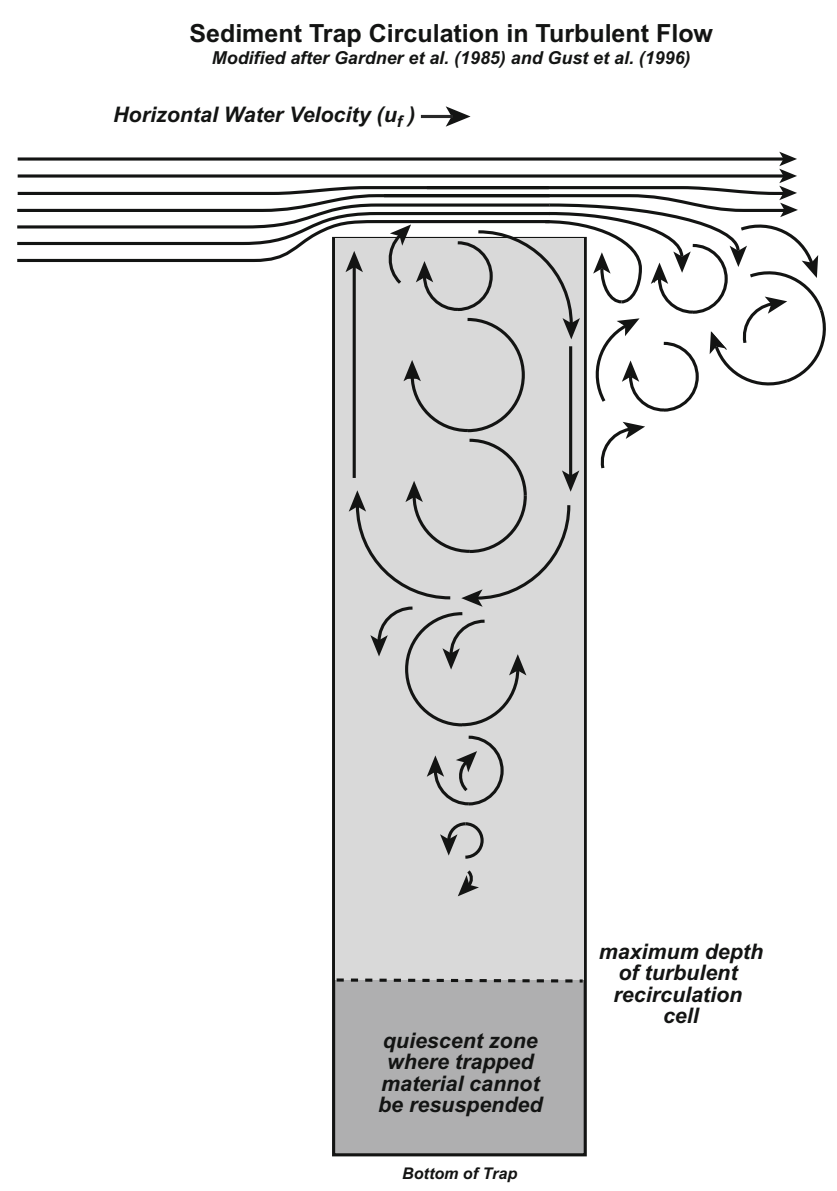

Fig. 3 Schematic view of circulation over and in a sediment trap as modified after Gardner et al. (1985) and Gust et al. (1996). Flow accelerates as it comes in proximity to the trap, separates, and accelerates away from the upstream edge of the trap mouth and sheds unsteady turbulent eddies over the mouth of the trap and into the trap. Flow in these eddies enter the trap on the downstream edge of the trap mouth, circulating upstream, and exiting the trap mouth at upstream inner edge of the trap mouth. The unsteady turbulent eddies that form over the mouth of the trap also propagate far down into the trap and downstream of the trap

In shallow-water $(<40 \mathrm{~m})$ environments that characterize most hermatypic coral reefs, this decrease in $P$ with an increase in $z_{o}$ is a function of the interaction of two different processes: the variation $u_{f}$ in the wave and current boundary layers, and the distribution of $N_{p}$ near the seabed. As shown by van Doorn (1981), $u_{f}$ most commonly increases in a logarithmic manner away from the seabed (Fig. 4a). The synthesis by Nielsen (1992) suggests that time-averaged profiles of $N_{p}$ under waves and currents typically decrease exponentially away from the seabed and are a function of $d$, with finer $d$ being greater in magnitude at a given height above the seabed due to its lower $w_{s}$, and coarser $d$ being smaller at the same height above the seabed due to its higher $w_{s}$ (Fig. 4b). The resulting horizontal flux of particles $(q)$, which is the product of $u_{f}$ and $N_{p}$, varies in magnitude with height above the seabed due to $d$ (Nielsen 1992). Because $q$ influences $P$ in energetic settings (e.g., Gardner 1980a; Butman 1986) and $q$ is strongly dependant on height above the seabed (Fig. $4 \mathrm{c}$ ), $z_{o}$ can strongly effect $P$. Together, this suggests that for a given set of environmental conditions $\left(u_{f}, d\right.$, etc.) and trap parameters $(H$ and $D)$, variations in $z_{o}$ would result in differences in $P$.

Finally, Gardner (1980b), Butman et al. (1986), and others make the point that sediment traps often only vaguely approximate the amount and type of sediment that is actually deposited on the seabed. In energetic environments that typically characterize coral reefs, resuspension is common (e.g., Ogston et al. 2004; Storlazzi et al. 2004, 2009b), resulting in inferred "sedimentation rates" that may greatly exceed those from the influx of new particles actually depositing and remaining on the seabed. Further, the flux of particles past a site $(q>0)$ should result in some accumulation in traps, even if the particles never actually settle on the seabed. Gardner (1980b) stated "the flux of new particles to the sediment surface is not necessarily equal to the net sedimentation rate of the region".

\section{Study area}

The data presented here come from four studies in two island chains in the north Pacific Ocean: the Hawaiian Islands in the north-central Pacific Ocean $\left(20-22^{\circ} \mathrm{N}\right.$, $156-160^{\circ} \mathrm{W}$ ), and from Guam in the Mariana Islands in the northwestern Pacific Ocean $\left(13^{\circ} \mathrm{N}, 145^{\circ} \mathrm{E}\right)$. The physical environment in both island chains are characterized by seasonal $5-10 \mathrm{~m} \mathrm{~s}^{-1}$ northeasterly trade winds that generate wave heights of 1 to $3 \mathrm{~m}$ with periods of 5 to $8 \mathrm{~s}$ and intermittent storms that generate wave heights of 3 to $6 \mathrm{~m}$ with periods of 10 to $18 \mathrm{~s}$. Both island chains have mixed, semi-diurnal microtidal regimes, with the mean daily tidal range of approximately $0.6 \mathrm{~m}$; the reefs that line these island's shores range in depth from 1 to $40 \mathrm{~m}$ and host coral communities that vary considerably in terms of health. The study areas of both Hawaii and Guam are considered wave-dominated sites, in that the mean horizontal wave-orbital velocities and resulting shear stresses were greater than the mean current velocities and stresses during the study periods. Thus, while these results might not be applicable to reef passages with very energetic currents or some back-reef lagoons and deep embayments protected from waves, they likely characterize most fore reefs that are exposed to storm waves and trade-wind waves. For more information on the study areas, please see Storlazzi et al. (2004, 2009a, b, 2010) and Bothner et al. (2006). 
Fig. 4 Schematic views of variations in flow, particle concentration, and the resulting flux with height $(z)$ above the seabed based on van Doorn (1981) and Nielsen (1992). a Horizontal flow velocity $\left(u_{f}\right)$. b The number of particles in the fluid per unit volume $\left(N_{p}\right)$ as a function of grain size $(d)$. c Horizontal particle flux $(q)$, the product of $u_{f}$ and $N_{p}$. Wave and current $u_{f}$ increase logarithmically away from the seabed then become more uniform with depth closer to the surface while $N_{p}$ decreases exponentially away from the seabed. The resulting $q$, which controls $N_{p}$ moving over the trap during a given time frame, increases rapidly away from the seabed, reaches a maximum value at some height controlled by $d$, then decays with distance above the bed (a)

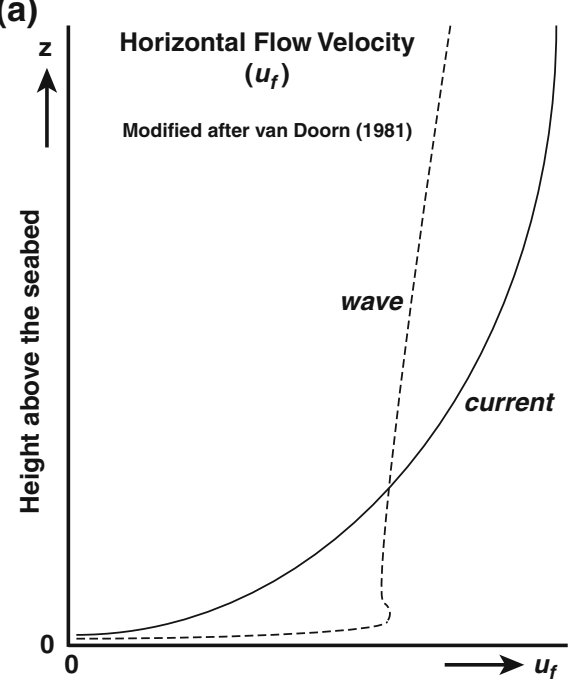

(b)

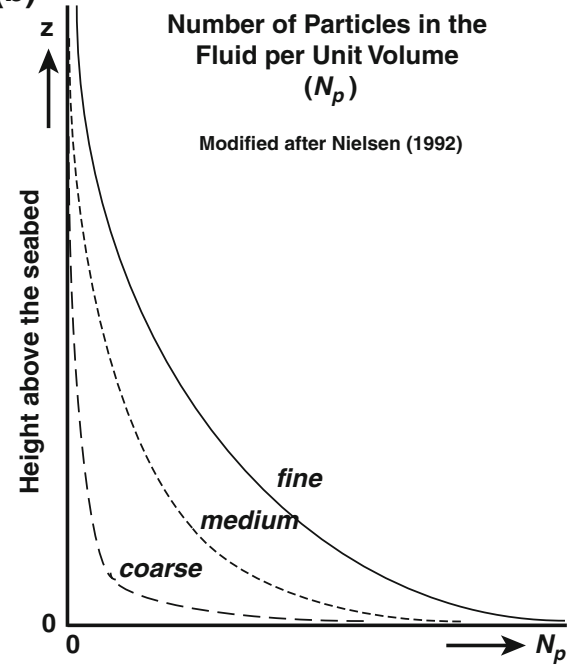

(c)

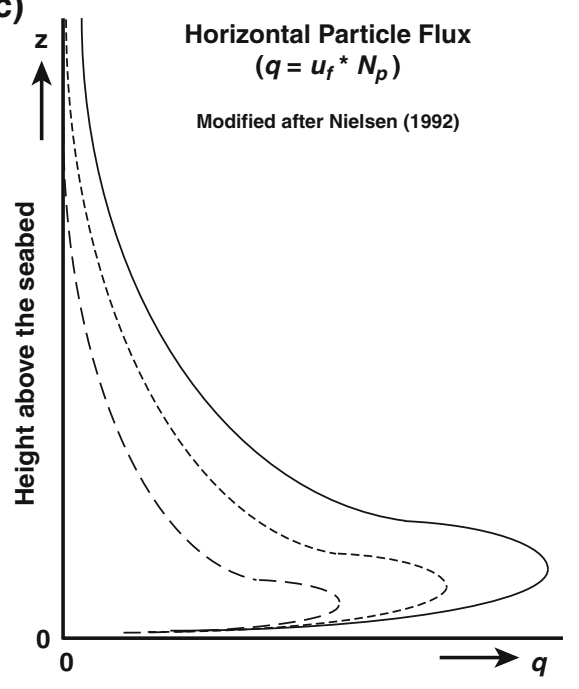

\section{Methods}

\section{Sediment collection}

Two types of sediment traps were used to collect suspendedsediment samples from the water column over coral reefs. Simple tube traps (STT), consisting of a plastic tube with $D=6.7 \mathrm{~cm}$ and $H=30$ or $60 \mathrm{~cm}$, were deployed with $z_{o}=40 \mathrm{~cm}$ or $80 \mathrm{~cm}$, respectively; while $H$ and $z_{o}$ were varied between experiments, all traps for a given field experiment had the same $H$ and $z_{o}$. Additional STTs were sometimes deployed with $z_{o}=140 \mathrm{~cm}$ to evaluate vertical gradients in trap collection rates. An 8-cm high baffle was placed in the top of each tube trap to reduce turbulence and minimize disturbance by aquatic organisms (Bothner et al. 2006). Programmable rotating sediment traps (RST) were deployed with $z_{o}=140 \mathrm{~cm}$. Each rotating trap consisted of a cylinder with dimensions of $D=20 \mathrm{~cm}$ and $H=75 \mathrm{~cm}$ equipped with a funnel in the lower $15 \mathrm{~cm}$ of the cylinder to direct settling sediment into one of 21 plastic bottles $(500 \mathrm{ml})$. Sampling bottles were mounted on a carousel that rotated a new bottle under the funnel every $\sim 4.5$ days. The average daily trap collection rate $(P)$ for both the STTs and RSTs was calculated by measuring the total mass of sediment in the trap or bottle and dividing by $A$ and the duration of the collection period. The STTs and RSTs were generally deployed on the order of $80-110$ days during the different experiments. It should be noted that these sediment trap deployments were designed to acquire suspended-sediment samples for compositional information and/or suspendedsediment flux calculations at specific locations and thus were not optimized for investigating the impacts of hydrodynamics and sediment dynamics on sediment trap dynamics.

Sediment grain size analysis was conducted on wet aliquots of the trap samples using sieving and Coulter counter techniques described by Poppe et al. (2000). Total carbon 
and carbonate carbon measurements were made using a Perkin Elmer CHN analyzer and a UIC coulometer, respectively. Total organic carbon (TOC) was determined by difference between total carbon and calcium carbonate $\left(\mathrm{CaCO}_{3}\right)$. Critical shear stresses for the different types of sediment were calculated using the modified Shield parameter method of Madsen (1999).

\section{Oceanographic data}

Instruments were deployed concurrently at sediment trap locations to collect hourly in situ time-series measurements of tides, waves, currents, and turbidity. In order to compare the combined effect of mean near-bed currents $\left(u_{\text {current }}\right)$ and horizontal wave-orbital velocities $\left(u_{\text {wave }}\right)$ to the data from the sediment traps, the combined horizontal flow velocity $\left(u_{f}\right)$ from the in situ data was calculated using Eq. 11. In order to determine whether the shear stress (force per unit area) applied by the waves and currents was a significant contributor to the sediment trap data, the total shear stress imparted on the seabed ( $\left.\tau_{\text {bed }}\right)$ was computed from the $u_{\text {wave }}$ and $u_{\text {current }}$ data using the method presented by Ogston et al. (2004) that accounts for the combined effects of waves and currents. Because of biofouling, high-resolution turbidity data for the duration of sediment trap deployments are limited.

Owing to the different goals of the various experiments, $u_{f}$ and turbidity were not always collected nor were the sediment samples always processed for both $d$ and sediment composition. Furthermore, it is important to highlight the large discrepancy in resolution of the datasets. The sediment traps provided one integrated sample of sediment that encompassed a range of $d$ and grain compositions, which resulted in variations in $\rho_{p}$ and $w_{s}$ for the period of deployment; the oceanographic instrumentation, on the other hand, provided hourly measurements of waves, current, flow, and sometimes turbidity. Thus, for the STTs, there were on average 2160 measurements of oceanographic parameters to compare to one sediment sample, and 108 oceanographic measurements for each of the samples from the RSTs (deployed for $\sim 90$ days and $\sim 4.5$ days, respectively). For more information on the sediment traps, oceanographic instruments, or data processing, please see Storlazzi et al. (2004, 2009a, b, 2010) and Bothner et al. (2006).

\section{Results}

Controls on trap collection rate $(P)$

Trap collection rate $(P)$ was compared to mean $u_{f}$ and mean $\tau_{\text {bed }}$ during the period of deployment for 20 STTs from four different reefs and 75 sample bottles from RSTs deployed at two locations each on two different reefs. $P$ increased exponentially with increasing $u_{f}$ and $\tau_{\text {bed }}$ on three of the four reefs studied (Fig. 5a). The correlation was greatest $\left(r^{2}=0.968 ; P<0.001\right)$ for the relatively continuous south Molokai fringing reef and lower for the Guam and Kauai reefs $\left(r^{2}=0.607\right.$ and 0.646 , respectively; both have $P<0.1$ level $)$ in an embayment, which are occasionally exposed to high sediment loads from local rivers. Interestingly, the data from Oahu show the opposite pattern of the data from the other three islands: $P$ decreased exponentially with increasing $u_{f}$ and $\tau_{\text {bed }}$; the correlation was significant $\left(r^{2}=0.799, P<0.02\right)$.

Using the RST data, at both of the exposed (higher $u_{f}$ or $\tau_{\text {bed }}$ ) sites (Fig. 5b), $P$ increased exponentially with increasing $u_{f}$ and $\tau_{\text {bed }}$; the correlation was greater $\left(r^{2}=0.681 ; P<0.001\right)$ for the south Kauai embayment and lower for the slightly less energetic south Molokai reef $\left(r^{2}=0.255 ; P<0.02\right)$. Both relatively quiescent (lower $u_{f}$ or $\left.\tau_{\text {bed }}\right)$ areas, however, show no significant trends in the data, with $p$ values for the correlations between $P$ and $u_{f}$ or $\tau_{\text {bed }}$ from both islands above 0.05 .

Owing to the numerous grain sizes of varying composition of the sediment collected in a given trap, we were unable to directly investigate the influence of $w_{s}$ (Eg. 2) on $P$. However, we utilized mean $d\left(d_{50}\right)$ as a proxy for $w_{s}$ by making the assumption that $\mu_{f}$ was relatively constant, and changes in $\rho_{p}$ relative to $\rho_{f}$ were small compared to the changes in $d$. The variation in $P$ as a function of $d_{50}$ collected during the period of deployment was explored for 11 STTs where both types of data were simultaneously collected. Along the fringing reef off Guam (Fig. 6), $P$ increased linearly with $d_{50}\left(r^{2}=0.850\right.$; $P<0.01)$. In the large embayment off Oahu, however, there was no significant relationship between $P$ and $d_{50}$ for all of the STTs; if the trap deployed in a location (site MP-5) where a stream directly discharged into a deep vertical notch in the otherwise gently sloping fringing reef (Storlazzi et al. 2010) is excluded from the analysis, $P$ increased linearly with $d\left(r^{2}=0.581 ; P<0.1\right)$.

While we did not have a direct measure of $N_{p}$, we utilized mean turbidity as a proxy for $N_{p}$. The variation in $P$ as a function of mean turbidity during the period of deployment was explored for 7 STTs and 42 sample bottles from RSTs at locations where both types of data were simultaneously collected. In the large embayment off Oahu (Fig. 7a), $P$ for STTs increased linearly with turbidity $\left(r^{2}=0.966 ; P<0.05\right)$. In the smaller embayment off Kauai, however, there was no significant relationship between $P$ and turbidity for STTs. The sample bottles from RST deployed in an exposed area off Kauai show a significant positive linear trend between $P$ and turbidity $\left(r^{2}=0.588 ; P<0.01\right)$, while the RST deployed in a quiescent area off Kauai displayed no significant relationship between $P$ and turbidity (Fig. 7b).

The variation in $P$ as a function of mean horizontal flux of particles ( $q$, Fig. $4 \mathrm{c})$ was investigated using turbidity as 
Fig. 5 Variations in trap collection rate $(P)$ as a function of the horizontal flow velocity $\left(u_{f}\right)$ and shear stress $\left(\tau_{\text {bed }}\right)$. a Data from simple tube traps (STTs) in four experiments. b Data from rotary sediment traps (RSTs) in two

experiments. In more energetic areas, there are positive relationships among $P$ and $u_{f}$ and $\tau_{\text {bed }}$; in more quiescent areas, there is no apparent relationship between $P$ and $u_{f}$ and $\tau_{\text {bed }}$
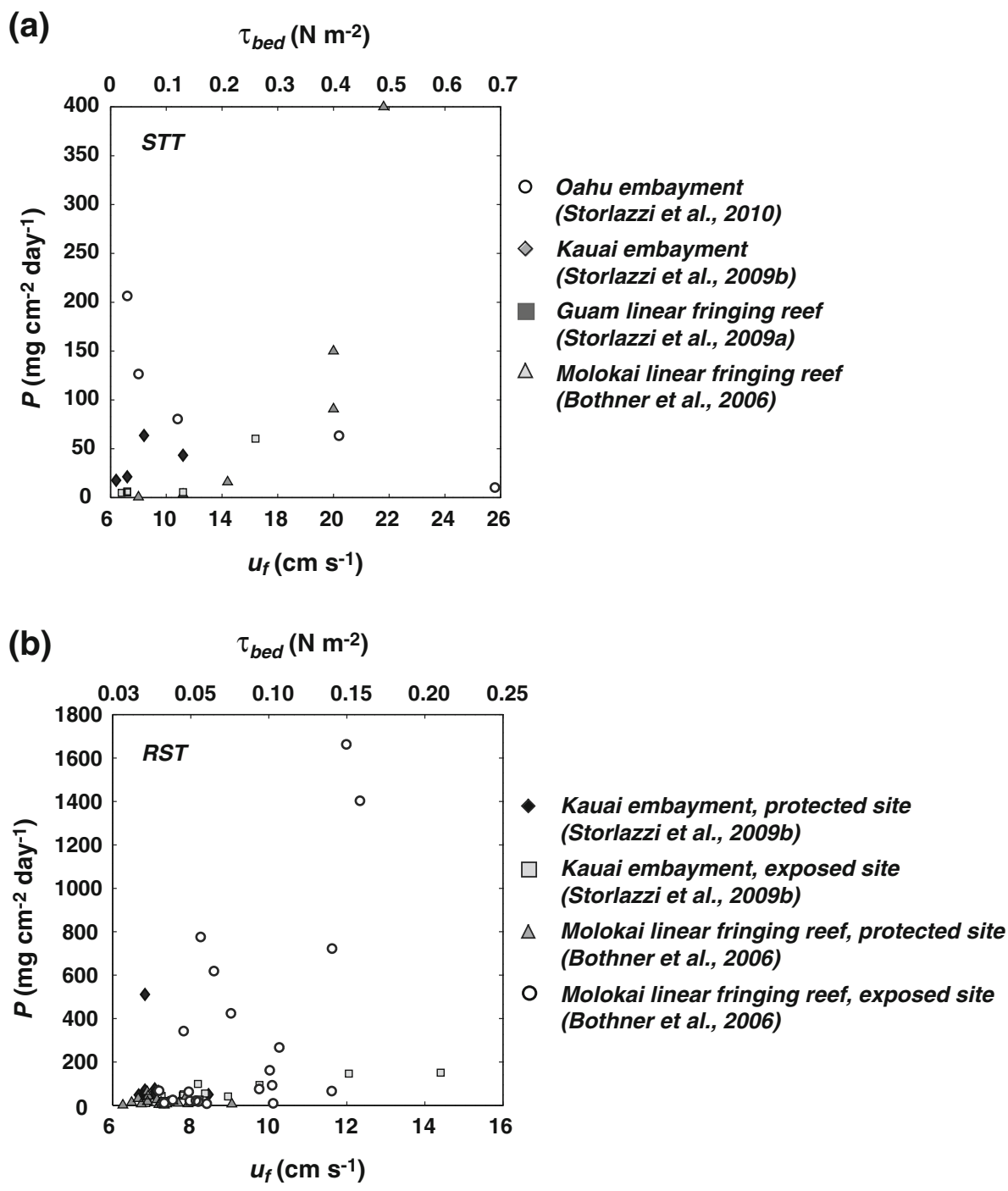

a proxy of $N_{p}$ to provide insight into contribution of the number of particles being transported over the top of the trap during a given time to $P$. The mean horizontal turbidity flux $(\sim q)$ during the period of deployment was explored for 7 STTs and 42 sample bottles from RSTs at both locations where both types of data were simultaneously collected. In the large embayment off Oahu (Fig. 8a), $P$ for STTs increased linearly with mean horizontal turbidity flux $\left(r^{2}=0.952 ; P<0.05\right)$. Unlike the relationship between $P$ and turbidity in the smaller embayment off Kauai, however, $P$ for STTs also increased linearly with horizontal turbidity flux $\left(r^{2}=0.869\right.$; $P<0.02)$. The sample bottles from RST deployed in an exposed area off Kauai show a significant positive linear trend between $P$ and horizontal turbidity flux $\left(r^{2}=0.832\right.$; $P<0.001$ ), while the RST deployed in a quiescent area off Kauai did not display a significant relationship between the two variables (Fig. 8b). Overall, the mean horizontal turbidity flux $(\sim q)$ explained, on average, greater than $13 \%$ more of the variability in $P$ than turbidity alone. Lastly, variability in $P$ as a function of height above the seabed was investigated using data from co-located sediment traps of the same design (same $H$ and $D$ ) at two locations off Kauai (Storlazzi et al. 2009b; data not shown here). The STT in a relatively quiescent location with $z_{o}=40 \mathrm{~cm}$ had a $P$ more than 2.5 times that of an adjacent STT of the same design with $z_{o}=140 \mathrm{~cm}$. Similarly, a STT in an energetic area with $z_{o}=40 \mathrm{~cm}$ had a $P$ approximately 14 times that of the STT with $z_{o}=140 \mathrm{~cm}$.

Controls on grain size and composition of trapped sediment

The composition of material collected in a sediment trap as a function of mean $u_{f}$ and $\tau_{\text {bed }}$ during the period of deployment was explored for 75 sample bottles from RSTs in four deployments. At the exposed site off Kauai (Fig. 9a), the percentage of sand-sized $(d>0.063 \mathrm{~mm})$ material collected 
- Oahu embayment (Storlazzi et al., 2010)

- Guam linear fringing reef (Storlazzi et al., 2009a)

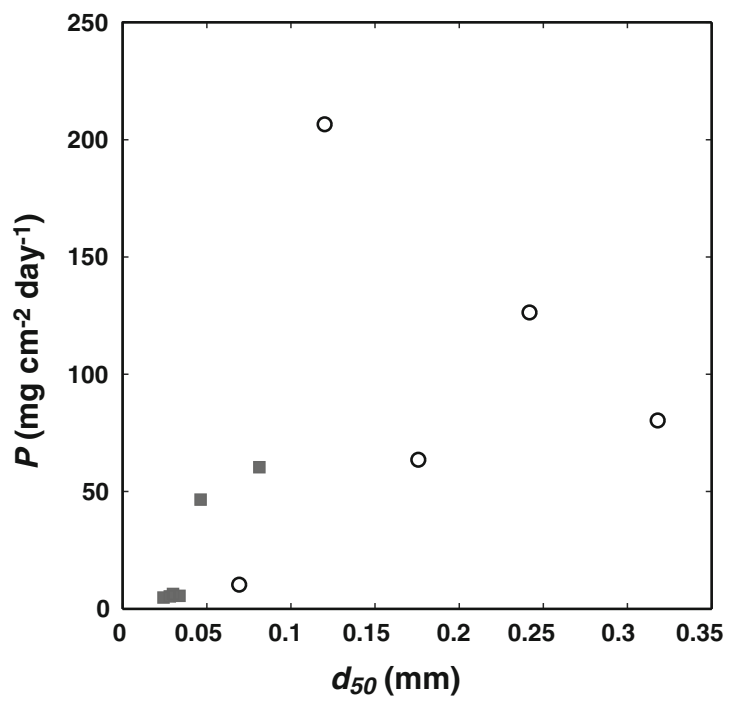

Fig. 6 Variations in trap collection rate $(P)$ as a function of the mean grain size $\left(d_{50}\right)$ from simple tube traps (STTs) in two experiments. There appear to be positive relationships between $P$ and $d$

was variable and did not correlate with increasing $u_{f}$ and $\tau_{\text {bed }}$ $\left(r^{2}=0.318 ; P\right.$ not significant $)$. Similarly, in relatively quiescent (low $u_{f}$ or $\tau_{\text {bed }}$ ) areas off Kauai and Molokai, no trends in $d$ with $u_{f}$ or shear stress were found.

A significant positive relationship between percent $\mathrm{CaCO}_{3}$ and $u_{f}$ and $\tau_{\text {bed }}\left(r^{2}=0.590 ; P<0.05\right.$; Fig. 9b) was found in the energetic (high $u_{f}$ or $\tau_{\text {bed }}$ ) area off Kauai. No significant relationship was found in the energetic area off Molokai $\left(r^{2}=0.135\right)$ or at the relatively quiescent sites. Similar to relationship between $\mathrm{CaCO}_{3}$ and $u_{f}$ and $\tau_{\text {bed }}$ at the more energetic sites, the RST in the more energetic area off Kauai displayed a significant inverse relationship between the percent TOC and $u_{f}$ and $\tau_{\text {bed }}\left(r^{2}=0.645 ; P<0.05\right.$; Fig. 9c). When the $u_{f}$ and $\tau_{\text {bed }}$ were low, more low-density TOC matter (with slower $w_{s}$ ) settled into the traps relative to $\mathrm{CaCO}_{3}$; at higher $u_{f}$ and $\tau_{\text {bed }}$, the RSTs showed bias against slow $w_{s}$ particles as the TOC was diluted by resuspended $\mathrm{CaCO}_{3}$. As stated earlier, the south Molokai reef is relatively continuous and not impacted by major river discharge, whereas the Kauai settings were in close $(<0.5 \mathrm{~km}$ and $2 \mathrm{~km}$ for the quiescent and energetic sites, respectively) proximity to a major river, and thus the linkages between the fluvial and coral reef systems were more direct.

Sediment grain size and composition: traps versus the seabed

Material collected in 16 STTs off Guam and Oahu was compared to that in grab samples collected from the
- Oahu embayment (Storlazzi et al., 2010)

$\diamond$ Kauai embayment (Storlazzi et al., 2009b)

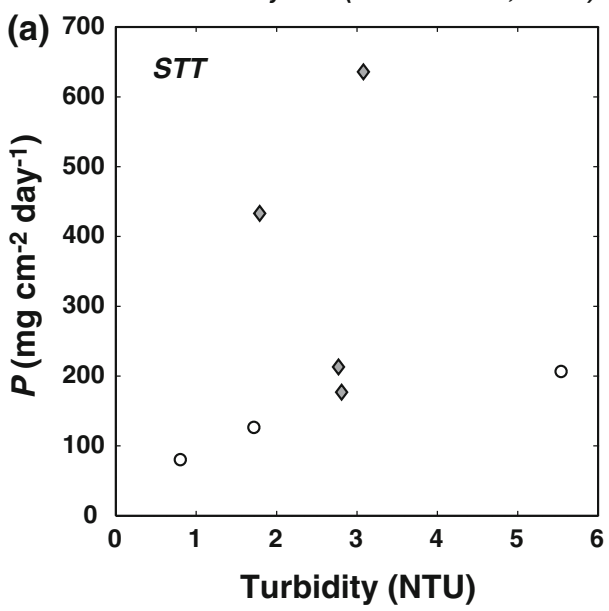

- Kauai embayment, protected site (Storlazzi et al., 2009b)

口 Kauai embayment, exposed site (Storlazzi et al., 2009b)

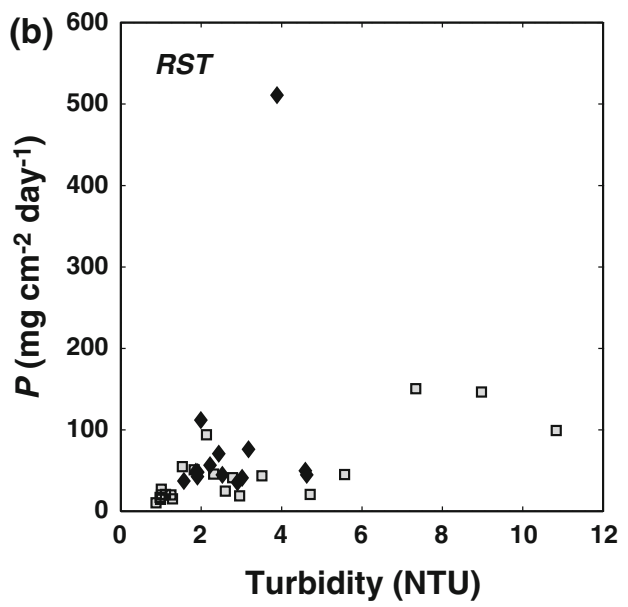

Fig. 7 Variations in trap collection rate $(P)$ as a function of the turbidity. a Data from simple tube traps (STTs) in two experiments. b Data from rotary sediment traps (RSTs) in one experiment. In more energetic areas, there appear to be positive relationships between $P$ and turbidity; in more quiescent areas, there is no apparent relationship between $P$ and turbidity

adjacent seabed. Interestingly, all of the samples displayed the same degree of differences between the material collected in the sediment traps and sediment on the adjacent seabed (Fig. 10). In all cases, the seabed had coarser $d$ than what was collected in the traps, with average differences of $8.2 \%$ more gravel-sized material, $19.2 \%$ more sand-sized material, $20.6 \%$ less silt-sized material, and $6.8 \%$ less clay-sized material. In terms of composition, the seabed had $2.7 \%$ more TOC and $22.3 \%$ more $\mathrm{CaCO}_{3}$ (and thus, conversely, less terrigenous material) than the adjacent sediment traps. Although there was variability in the sediment class percentages by mass for each of the different trap locations, all 16 locations displayed similar differences between trap and seabed sediment in sign and magnitude. 
(a) ○ Oahu embayment (Storlazzi et al., 2010)

$\diamond$ Kauai embayment (Storlazzi et al., 2009b)

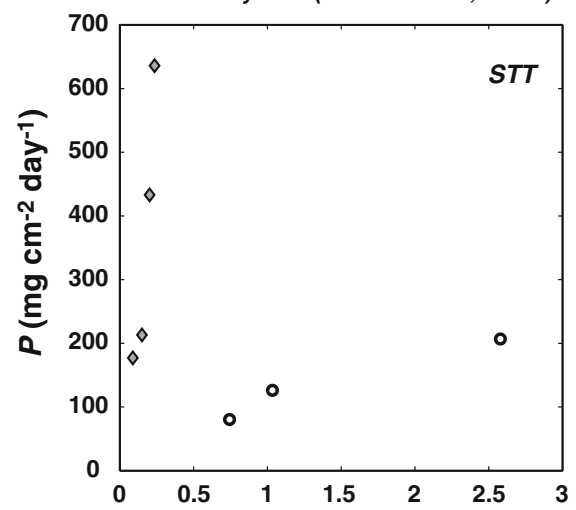

Horizontal Turbidity Flux $\sim q\left(\right.$ NTU $\left.\mathrm{cm} \mathrm{s}^{-1}\right)$

(b) Kauai embayment, protected site (Storlazzi et al., 2009b)

$\square$ Kauai embayment, exposed site (Storlazzi et al., 2009b)

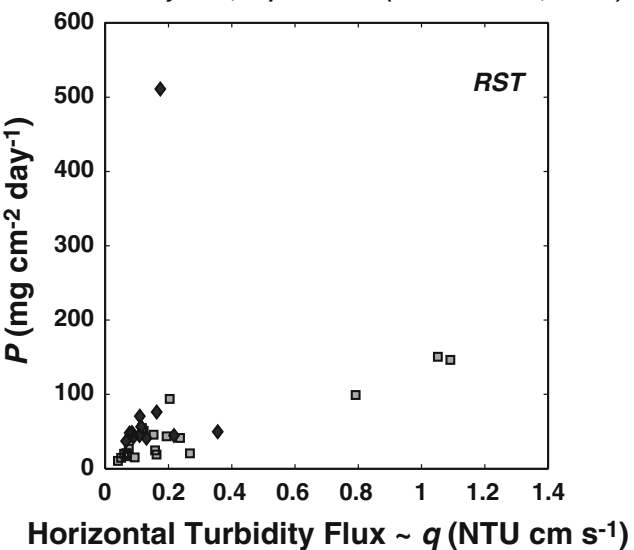

Fig. 8 Variations in trap collection rate $(P)$ as a function of mean horizontal turbidity flux $(\sim q$, Fig. 4 c), using turbidity as a proxy of $N_{p}$ to provide insight into contribution of the number of particles being transported over the top of the trap during a given time to $P$. a Data from simple tube traps (STTs) in two experiments. b Data from rotary sediment traps (RSTs) in one experiment. In more energetic areas, there appear to be positive relationships between $P$ and mean horizontal turbidity flux; in more quiescent areas, there is no apparent relationship between the two variables. The mean horizontal turbidity flux $(\sim q)$ explained, on average, greater than $13 \%$ more of the variability in $P$ than turbidity alone

\section{Discussion}

Overall, our results show some patterns that are critical for understanding the information provided by sediment traps in coral reef settings. In more energetic areas, there appear to be positive relationships among $P, u_{f}, \tau_{\text {bed }}, d$, turbidity, and $q$ and possibly relationships between $d$, percent $\mathrm{CaCO}_{3}$, and percent TOC and $u_{f}$ and $\tau_{\text {bed. }}$. These relationships suggest resuspension of material on the seabed may be an important contributor to $P, d$, and composition of the material collected in near-bed sediment traps in energetic areas. Conversely, in more quiescent areas, there are no clear relationships between $P$ and $u_{f}$, $\tau_{\text {bed }}$, turbidity, $d$, or composition, suggesting that advection of material from elsewhere might influence $P, d$, and grain composition more than resuspension of material from the seabed. Although our data are limited, it also appears that $P$ in both more energetic and more quiescent areas is inversely related to $z_{o}$, similar to the observations made by Gardner et al. (1983). Together, this suggests that hydrodynamics, which vary significantly over relatively short distances in coral reef environments in both space and time (e.g., Wolanski 1994; Storlazzi et al. 2009b), strongly influence $P$ and the composition of the material collected in sediment traps on hermatypic coral reefs.

The differences between the composition of sediment collected in traps and sediment collected on the adjacent seabed are important for a number of reasons. First, it highlights that sediment traps do not measure net vertical sediment flux to, and accumulation on, the coral reef surface, for if this were the case the $d$ and composition of the material in the sediment trap would match that on the seabed. This discrepancy occurs because material falling into a sediment trap has a much lower potential for resuspension than the same material that settles on the adjacent reef surface, as suggested by Bothner et al. (2006). Thus, the use of "sedimentation rate" instead of "trap collection rate" or "trap accumulation rate" for $P$ therefore appears incorrect. Traps collect a somewhat biased sample of the material being transported through the system, and this material may never settle on the seabed at the site. A good example of this is provided by imagery of the RST and its collection bottles before and after the 2006 deployment off Kauai (Storlazzi et al. 2009b). The underwater photographs of the RST at the beginning (Fig. 11a) and end (Fig. 11b) of the deployment show a relatively clean carbonate sandy seabed with less than $2 \%$ by mass of terrigenous (volcanic) mud $(d<0.063 \mathrm{~mm})$. Approximately $8 \mathrm{~cm}$ of carbonate sand accumulated under the tripod, perhaps with migrating sand waves (e.g., bed load), to cover the weights that help anchor the trap assembly during the course of the deployment. The sediment collected in the RST's bottles (Fig. 11c), however, was dark brown and contained more than $60 \%$ terrigenous mud by mass, and this mud was clearly not residing on the seabed at the site during the deployment or recovery of the RST. This difference in composition and rate of accumulation suggest that sediment trap collection rates do not predict net accumulation on the seabed.

Sediment are traps expected to preferentially collect coarser $d$ because of their higher $w_{s}$ than finer particles, especially farther above the seabed where $u_{f}$ is greater (e.g., Gardner et al. 1983; Baker et al. 1988). The presence of significant volumes of finer (small $d$ ) material in sediment traps, especially when the seabed is substantially coarser, 
Fig. 9 Variations in the trapped material grain size $(d)$ and composition as a function of the horizontal flow velocity $\left(u_{f}\right)$ and shear stress $\left(\tau_{\text {bed }}\right)$ from rotary sediment traps (RSTs) in two experiments. a Percentage of sand $(d>0.063 \mathrm{~mm})$ by mass. b Percentage of calcium carbonate $\left(\mathrm{CaCO}_{3}\right)$ by mass. c Total organic carbon (TOC) by mass. In more energetic (higher $u_{f}$ and $\tau_{\text {bed }}$ ) areas, there appear to be positive relationships between percentage of sand and $\mathrm{CaCO}_{3}$ and $u_{f}$ and shear stress, and a negative relationship between TOC and $u_{f}$ and $\tau_{\text {bed. }}$. In more quiescent (lower $u_{f}$ and $\tau_{\text {bed }}$ ) areas, there are no apparent relationships between these parameters

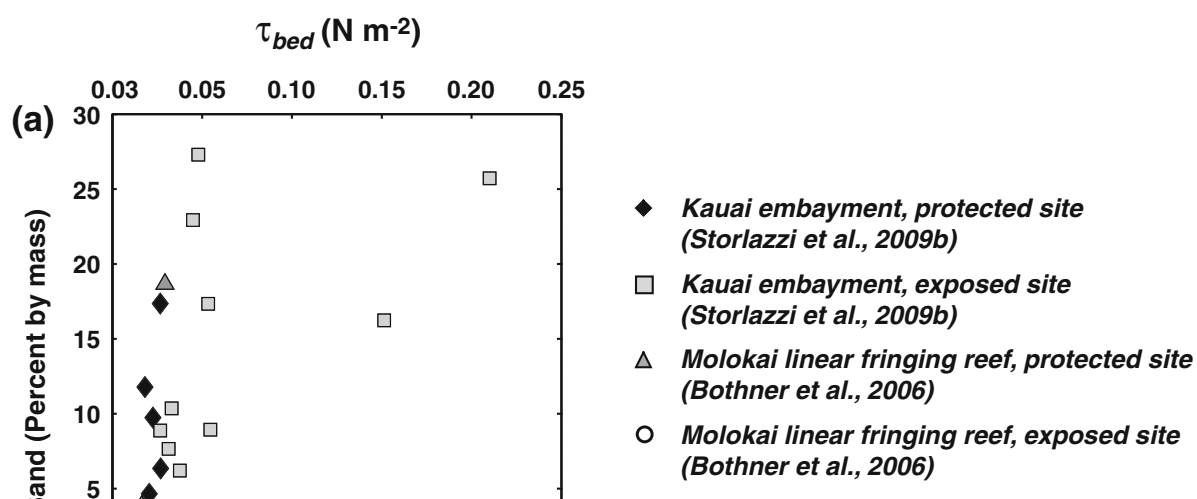

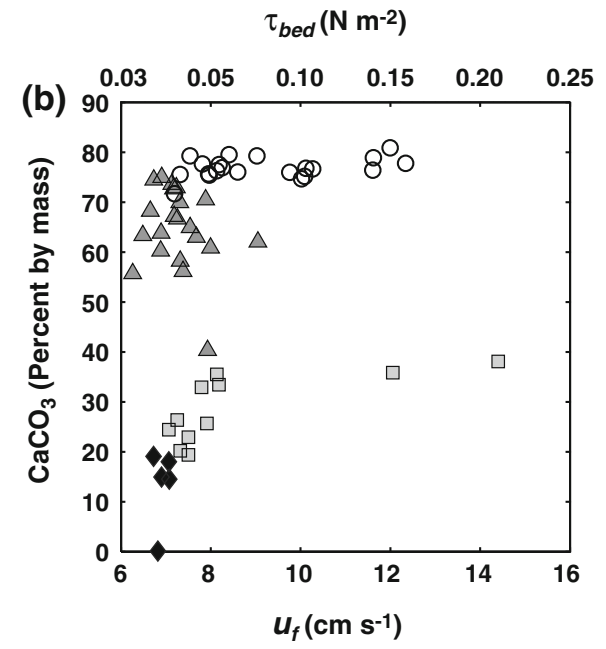

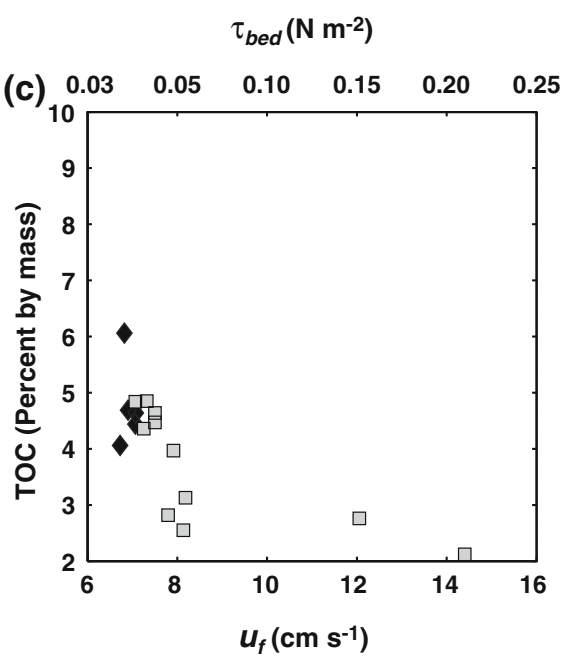

suggests that significant volumes (high $N_{p}$ ) of small $d$ sediment had advected through the area even though these particles do not reside on the seabed. Although small $d$ material may not be observed on the seabed during the sampling period, it is likely suspended in waters over the reef, with the potential consequence of decreasing photosynthetically active radiation (PAR) and desorbing nutrients and/or contributing toxicants.

Interestingly, the influence of sediment trap design and energetics on sediment trap collection rates were first addressed about three decades ago (e.g., Tooby et al. 1977; Gardner 1980a, b; Butman et al. 1986), yet sediment traps are still commonly used in shallow coral reef environments that typically are much more energetic than the deep sea. Many authors have suggested that sediment traps should not be employed in $u_{f}$ greater than $20 \mathrm{~cm} \mathrm{~s}^{-1}$, yet typical current speeds in many coral reef environments often exceed $20 \mathrm{~cm} \mathrm{~s}^{-1}$ (e.g., Wolanski 1994; Lugo-Fernandez et al. 1998; Storlazzi et al. 2004). The complications of trap dynamics discussed by Gardner et al. (1983), White (1990),
Jurg (1996), and others, however, do not include the effects introduced by waves that not only have wave-orbital velocities that generate $u_{f}$ greater than $20 \mathrm{~cm} \mathrm{~s}^{-1}$, but also because these orbital motions are flattened near the seabed, they result in fluid accelerations and decelerations over the mouth of the trap. Hydrodynamic models that describe trapping efficiency under accelerating and decelerating wave-induced motions and predict collection rates for a range of grain sizes are currently not available.

The limitations in applying sediment trap data to estimates of net sedimentation rates on a reef surface are rarely discussed in the literature. This should be a concern to the coral reef research community, for many researchers and regulatory agencies use sediment traps as the standard methodology for monitoring sedimentation in coral reef environments (Pernetta 1993; Rogers et al. 1994; Almada-Villela et al. 2003; Wilkinson et al. 2003; Hill and Wilkinson 2004; Jordan et al. 2010). The findings presented here, along with previous studies addressed earlier, suggest the following protocols for using sediment traps in coral reef environments: 
Fig. 10 Differences between the material collected in simple tube traps (STTs) during two experiments, offshore Guam and Oahu, compared to that of the adjacent seabed. The black circle and thin, black error bars denote the mean \pm 1 standard deviation; the thick gray lines denote the total range of the data. The seabed in all cases collected more gravel, more sand, less silt, and less clay. In terms of composition, the seabed always had more total organic carbon (TOC) and more calcium carbonate $\left(\mathrm{CaCO}_{3}\right)$ and thus, conversely, less terrigenous material than the adjacent sediment traps

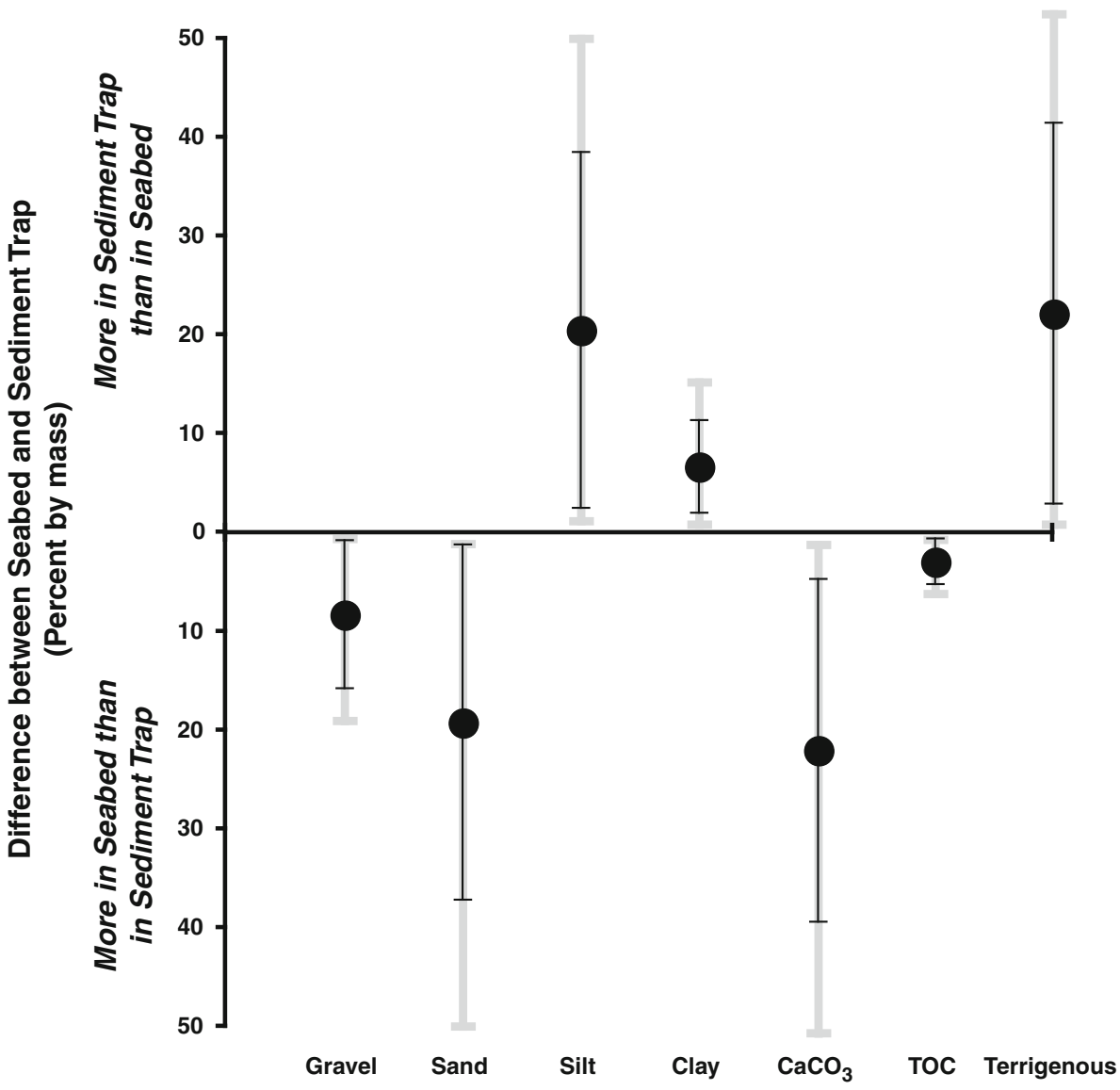

1. Sediment traps should be cylindrical, have $D$ greater than $5 \mathrm{~cm}$, and $R_{t}$ greater than 5:1, preferably greater than 7:1 in areas where high collection rates in the trap reduce the effective $R_{t}$ during the deployment period (e.g., Gardner 1980a, b; Butman 1986; Baker et al. 1988; White 1990; Gust et al. 1996; Jurg 1996; and, Bale 1998).

2. Sediment traps should be deployed with their trap mouths as the highest point in the flow so the trap mouths are not downstream of turbulent wakes caused by the structure (e.g., posts, rebar) used to secure the trap in its location (e.g., Tooby et al. 1977; Gardner 1980a, b; Butman 1986; Butman et al. 1986; and, Gust et al. 1996).

3. In experiments that use multiple traps, all traps should have the same $H, D$, and resulting $R_{t}$ (e.g., Gardner 1980a, b; Butman 1986; Butman et al. 1986; and, Gust et al. 1996).

4. In experiments that use multiple traps, all traps should be deployed at least $10 \mathrm{D}$ away from adjacent traps (e.g., Gardner 1980a; Nodder and Alexander 1999).

5. In experiments that use multiple traps, all traps should be deployed with their mouths at the same $z_{o}$ (data provided here; theory)

6. If possible, a sample of the surrounding seabed material should be processed using the same methods used on the material collected in the sediment trap. This will aid in identifying the source (e.g., resuspension of seabed material or advected from elsewhere) of the trapped material (data provided here).

7. The amount of particles collected in the trap over the duration of the deployment should be properly referred to as a "trap collection rate" or "trap accumulation rate" rather than a "sedimentation" rate. Sediment traps do not measure net sedimentation in a shallow, energetic marine system (theory).

8. In locations where the instantaneous combined current and wave-orbital speeds (and thus resulting $u_{f}$ ) are greater than $10-20 \mathrm{~cm} \mathrm{~s}^{-1}$ or sufficient to resuspend the adjacent seabed material (often as evident by a rippled seabed or noticeable wave surge at the sea floor), the trapped material should only be used to provide samples of suspended sediment for physical and chemical analyses to compare to seabed samples if hydrodynamic data are unavailable (theory).

9. Comparison of "trap collection rate" or "trap accumulation rate" from sediment traps of different design $(H, D$, or $\left.R_{t}\right)$, different deployment parameters $\left(z_{o}\right)$, or different locations $(d)$ should not be made without conducting a specific calibration experiment. The experiment should include traps of different designs in a single location 


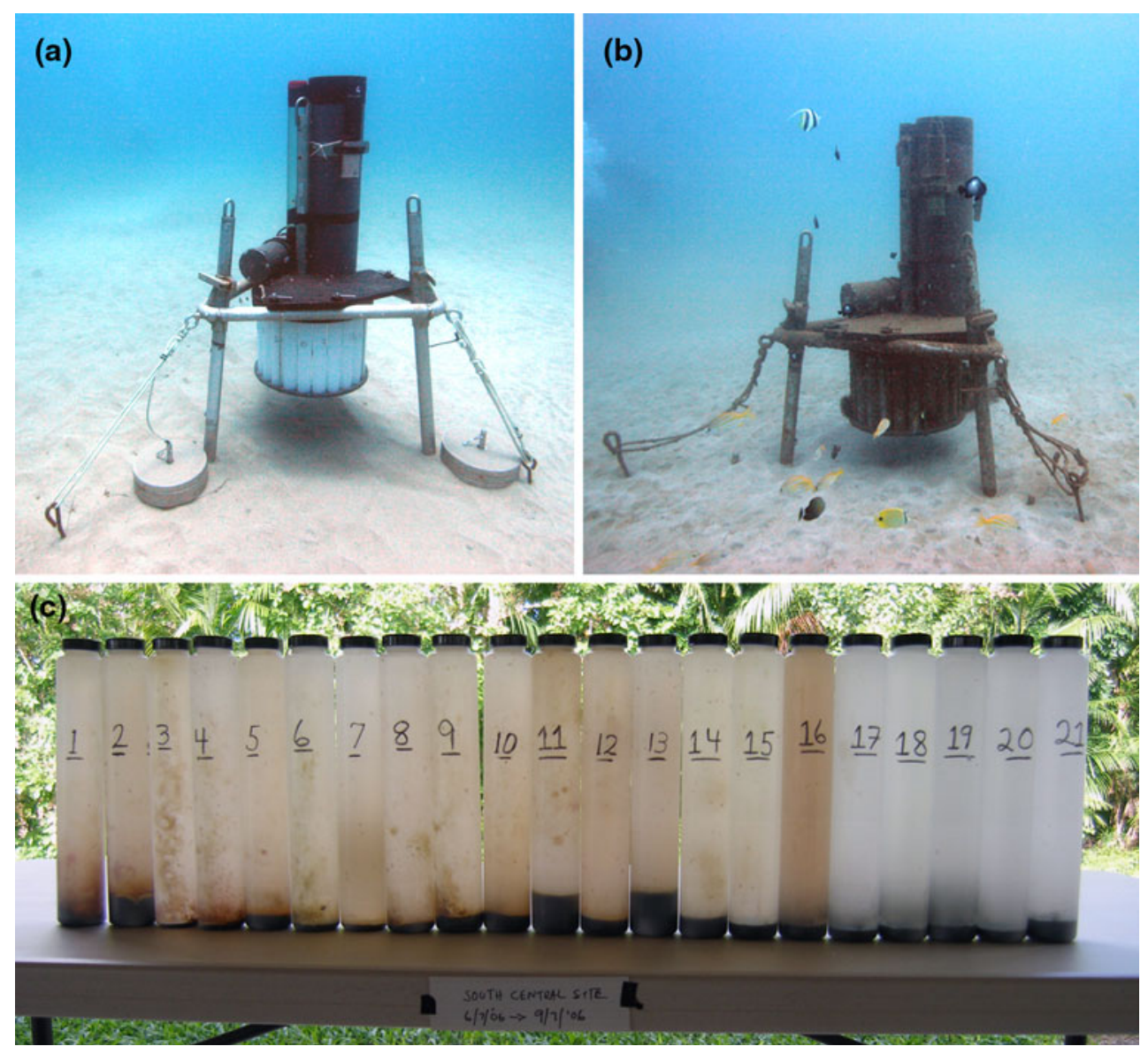

Fig. 11 Photographs showing that sediment traps often acquire a sample of the material being transported through the system rather than what is stable on the seabed (causing deposition, i.e., "sedimentation") at the site. a Underwater photograph of a rotary sediment trap (RST) at the time of deployment off Kauai in 2006 (Storlazzi et al. 2009b). b Underwater photograph of the same RST at the end of the deployment. c Photograph of the RST collection bottles. The photographs of the RST at the beginning and end of the deployment show a relatively clean carbonate sandy seabed and by the end of the deployment approximately $8 \mathrm{~cm}$ of accumulation at the base of the RST. The collection bottles contain dark brown sediment consisting primarily of volcaniclastic terrigenous mud that is not visible on the seabed

limitations discussed in this paper must be considered when the sediment trap results are interpreted. In light of our analyses, we recommend that prior research results in the literature be interpreted carefully and with recognition that there may be irregularities in the trapping technique or in the application to understanding coral reef processes.

Acknowledgments This work was carried out as part of the US Geological Survey's Coral Reef Project as part of an effort in the United States and its trust territories to better understand the effects of geologic processes on coral reef systems. Joshua Logan, Rick Rendigs, Kathy Presto, Thomas Reiss, and David Gonzales (USGS) assisted with the fieldwork and instrumentation. Michael Torresan, Michael Casso, Sandra Baldwin, Olivia Buchan, Harland Goldstein, Kate Mc Mullen, Jiang Xiao (USGS) and Steve Manganini (WHOI) performed the laboratory analyses on the sediment samples. We would also like to thank Amy Draut (USGS), Jon Warrick (USGS), and two anonymous reviewers who contributed numerous excellent suggestions and a timely review of our work. 
Open Access This article is distributed under the terms of the Creative Commons Attribution Noncommercial License which permits any noncommercial use, distribution, and reproduction in any medium, provided the original author(s) and source are credited.

\section{References}

Acevedo RJ, Morelock J, Olivieri RA (1989) Modification of coral reef zonation by terrigenous sediment stress. Palios 4:92-100

Aller RC, Dodge RE (1974) Animal sediment relations in a tropical lagoon, Discovery Bay, Jamaica. J Mar Res 32:209-232

Almada-Villela PC, Sale PF, Gold-Bouchot G, Kjerfve B (2003) Manual of methods for the Mesoamerican barrier reef systems synoptic monitoring program: Selected methods for monitoring physical and biological parameters for use in the Mesoamerican region. Mesoamerican Barrier Reef Systems Project Coordinating Unit, Belize City

Baker ET, Milburn HB, Tennant DA (1988) Field assessment of sediment trap efficiency under varying flow conditions. J Mar Res 46:573-592

Bale AJ (1998) Sediment trap performance in tidal waters: Comparison of cylindrical and conical collectors. Cont Shelf Res 18:1401-1418

Bastidas C, Bone D, Garcia EM (1999) Sedimentation rates and metal content of sediments in a Venezuelan coral reef. Mar Pollut Bull 38(1):16-24

Bloesch J, Burns NM (1980) A critical review of sedimentation trap technique. Schweizerische Zeitschrift fur Hydrologie 42:15-55

Bothner MH, Reynolds RL, Casso MA, Storlazzi CD, Field ME (2006) Quantity, composition and source of sediment collected in sediment traps along the fringing coral reef off Molokai, Hawaii. Mar Pollut Bull 52(9):1034-1047

Butman CA (1986) Sediment trap biases in turbulent flows: Results from a laboratory flume study. J Mar Res 44:645-693

Butman CA, Grant WD, Stolzenbach KD (1986) Prediction of sediment trap biases in turbulent flows: A theoretical analysis based on observations from the literature. J Mar Res 44:601-644

Crabbe MJC, Smith DJ (2005) Sediment impacts on growth rates of Acropora and Porites corals from fringing reefs of Sulawesi, Indonesia. Coral Reefs 24:437-441

Dickson KL, Maki AW, Brungs WA (1987) Fate and effects of sediment-bound chemicals in aquatic systems. Pergamon Press, New York

Dodge RE, Aller RC, Thompson J (1974) Coral growth related to suspension of bottom sediments. Nature 247:574-577

Fabricius KE (2005) Effects of terrestrial runoff on the ecology of corals and coral reefs: review and synthesis. Mar Pollut Bull 50:125-146

Fortes M (2000) The effects of siltation on tropical coastal ecosystems. In: Wolanski E (ed) Oceanographic processes of coral reefs. CRC Press, Boca Raton, pp 93-112

Gardner WD (1980a) Sediment trap dynamics and calibration: A laboratory evaluation. J Mar Res 38:17-39

Gardner WD (1980b) Field assessment of sediment traps. J Mar Res $38: 41-52$

Gardner WD, Richardson MJ, Hinga KR, Biscaye PE (1983) Resuspension measured with sediment traps in a high-energy environment. Earth Planet Sci Lett 66:262-278

Gardner WD, Southard JB, Hollister CD (1985) Sedimentation, resuspension and chemistry of particulates in the northwest Atlantic. Mar Geol 65:199-242

Gust G, Bowles W, Giordano S, Huttel M (1996) Particle accumulation in a cylindrical sediment trap under laminar and turbulent steady flow: An experimental approach. Aquat Sci 58(4):297-326
Hakanson L, Floderus S, Wallin M (1989) Sediment trap assemblages-a methodological description. Hydrobiologia 176(177):481-490

Hargrave BT, Burns NM (1979) Assessment of sediment trap collection efficiency. Limnol Oceanogr 24:1124-1136

Hill J, Wilkinson C (2004) Methods for ecological monitoring of coral reefs, Version 1. A resource for managers. Australian Institute of Marine Science, Townsville, Australia

Jordan LKB, Banks KW, Fisher LE, Walker BK, Gilliam DS (2010) Elevated sedimentation on coral reefs adjacent to a beach nourishment project. Mar Pollut Bull 60(2):261-271

Jurg B (1996) Toward a new generation of sediment traps and a better measurement/understanding of settling particle flux in lakes and oceans: A hydrodynamical protocol. Aquat Sci 58(4):283-296

Kench PS (1997) Contemporary sedimentation in the Cocos (Keeling) Islands, Indian Ocean: interpretation using settling velocity analysis. Sediment Geol 114:109-130

Lugo-Fernandez A, Roberts HH, Wiseman WJ, Carter BL (1998) Water level and currents of tidal and infragravity periods at Tague Reef, St. Croix (USVI). Coral Reefs 17:343-349

Madsen OS (1999) Coastal sediment transport processes. American Society of Civil Engineers Short Course, Coastal Sediments '99 Conference, New York

Mallela T, Perry CT (2007) Calcium carbonate budgets for two coral reefs affected by different terrestrial runoff regimes, Rio Bueno, Jamaica. Coral Reefs 26:129-145

Maragos JE (1972) A study of the ecology of Hawaiian reef corals. Ph.D. Thesis, University of Hawaii

Nielsen P (1992) Coastal bottom boundary layers and sediment transport. Singapore, World Scientific Publishing Co., World Scientific Advanced Series on Ocean Engineering 4

Nodder SD, Alexander BL (1999) The effects of multiple trap spacing, baffles, and brine volume on sediment trap efficiency. J Mar Res 57:537-559

Nugues MM, Roberts CM (2003) Coral mortality and interaction with algae in relation to sedimentation. Coral Reefs 22:507-516

Ogston AS, Storlazzi CD, Field ME, Presto MK (2004) Currents and suspended sediment transport on a shallow reef flat: Southcentral Molokai, Hawaii. Coral Reefs 23:559-569

Pernetta JC (ed) (1993) Monitoring coral reefs for global change, A marine conservation and development report. International Union for Conservation of Nature and Natural Resources, Gland, Switzerland

Poppe LJ, Elaison AH, Fredericks JJ, Rendigs RR, Blackwood D, Polloni CF (2000) Grain size analysis of marine sediments: methodology and data processing. In: U.S. Geological Survey East Coast sediment analysis: Procedures, database, and georeferenced displays. U.S. Geological Survey Open File Report 00-358 http://pubs.usgs.gov/of/2000/of00-358/

Randall RH, Birkeland CE (1978) Guam reefs and beaches, II: Sedimentation studies at Fouha Bay and Ylig Bay. University of Guam Marine Lab Technical Report 47

Reynolds CS, Wiseman SW, Gardner WD (1980) An annotated bibliography aquatic sediment traps and trapping methods. Freshwater Biology Association Publication 11

Rogers CS (1990) Responses of coral reefs and reef organisms to sedimentation. Mar Ecol Prog Ser 62:185-202

Rogers CS, Garrison G, Grober R, Hillis ZM, Franke MA (1994) Coral reef monitoring manual for the Caribbean and Western Atlantic. US National Park Service, monitoring manual

Saouter E, Campbell PG, Ribeyre F, Boudou A (1993) Use of partial extractions to study mercury partitioning on natural sediment particles- a cautionary note. Int J Environ Anal Chem 54:57-68

Shepard FP (1963) Submarine geology, 2nd ed. Harper and Row, New York, New York

Storlazzi CD, Ogston AS, Bothner MH, Field ME, Presto MK (2004) Wave- and tidally-driven flow and sediment flux across a 
fringing coral reef: South-central Molokai, Hawaii. Cont Shelf Res 24(12): 1397-1419

Storlazzi CD, Presto MK, Logan JB (2009a) Coastal circulation and sediment dynamics in War-in-the-Pacific National Historical Park, Guam. Measurements of waves, currents, temperature, salinity, and turbidity: June 2007-January 2008. USGS OpenFile Report 2009-1195 http://pubs.usgs.gov/of/2009/1195/

Storlazzi CD, Field ME, Bothner MH, Presto MK, Draut AE (2009b) Controls on sediment dynamics in a coral reef embayment: Hanalei Bay, Kauai. Mar Geol 264:140-151

Storlazzi CD, Presto MK, Logan JB, Field ME (2010) Coastal circulation and sediment dynamics in Maunalua Bay, Oahu, Hawaii. Measurements of waves, currents, temperature, salinity, and turbidity: November 2008-February 2009. USGS Open-File Report 2010-1217 http://pubs.usgs.gov/of/2010/1217/
Tooby PF, Wick GL, Isaacs JD (1977) The motion of a small sphere in a rotating velocity field: A possible mechanism for suspending particles in turbulence. J Geophys Res 82:2096-2100

van Doorn T (1981) Experimental investigation of near-bottom velocities in water waves with and without a current. Delft Hydraulic Laboratory TOW Report M-1423, Part I, Delft, The Netherlands

White J (1990) The use of sediment traps in high-energy environments. Mar Geophys Res 12:145-152

Wilkinson C, Green A, Almany J, Dionne S (2003) Monitoring coral reef marine protected areas, Version 1. A practical guide on how monitoring can support effective management of MPAs. Australian Institute of Marine Science, Townsville, Australia and IUCN Global Marine Program, Gland 1196, Switzerland

Wolanski E (1994) Physical oceanographic processes of the Great Barrier Reef. CRC Press, Boca Raton 